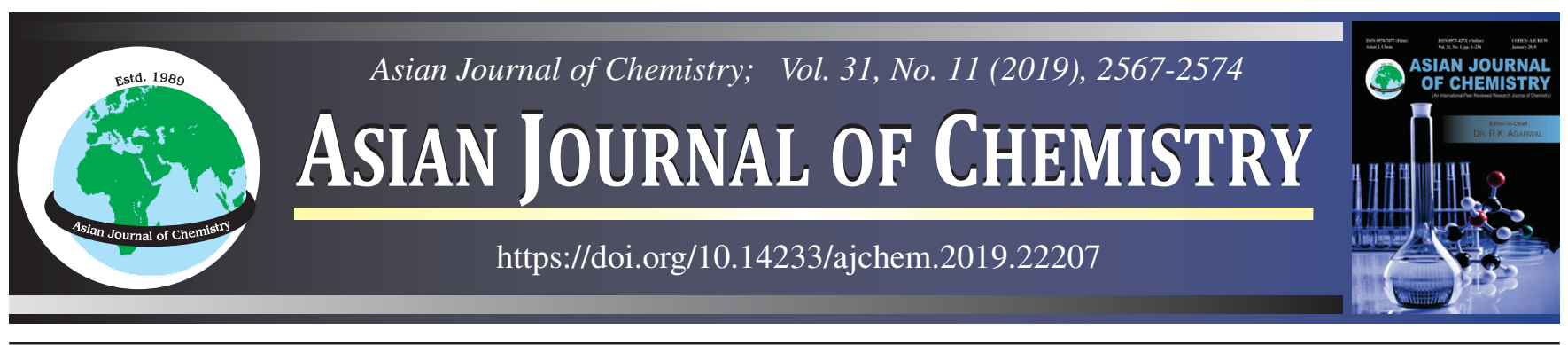

\title{
Fresh Neem Leaves (Azadirachta indica A. Juss) Extraction and Application: An Optimization using Response Surface Methodology
}

\author{
E. Rahayuningsin ${ }^{1, *}$, I.S. Subagya ${ }^{1}$, F.A. Setiawan ${ }^{2, \bullet}$ and H.T.B.M. Petrus ${ }^{1}$
}

${ }^{1}$ Department of Chemical Engineering, Universitas Gadjah Mada, Jalan Grafika No. 2 Kampus UGM, Yogyakarta 55281, Indonesia

${ }^{2}$ Department of Chemical Engineering, Universitas Jember, Jalan Kalimantan No. 37 Kampus Tegalboto, East Java 68121, Indonesia

*Corresponding author: Tel.: +62 81328841 483; E-mail: edia_rahayu@ugm.ac.id

Received: 21 May 2019;

Accepted: 25 June 2019;

Published online: 28 September 2019;

AJC-19587

| Fresh neem leaves (Azadirachta indica A. Juss) consist of quercetin (flavonoid) compound, responsible for yellow colour as a natural dye. The study investigated the variable optimization in fresh neem leaf extraction process and its application. The optimization was conducted using response surface methodology (RSM) and ANOVA test. The coefficients of determination $\left(\mathrm{R}^{2}\right)$ were generalized at 96.46 and 96.39

$\%$ for optimizing extraction process and application process parameter of natural dyes from neem leaves, respectively. The optimum variables for the extraction process were obtained at $50 \% \mathrm{w} / \mathrm{v}$ feed-solvent ratio, the temperature of $80{ }^{\circ} \mathrm{C}$ and extraction duration of $80 \mathrm{~min}$ with the response concentration of $46.19 \mathrm{~g} / \mathrm{L}$. Furthermore, the optimum variable on the application of natural dyes from neem leaves was recorded when alum was applied as fixator as much as $14.09 \mathrm{~g} / \mathrm{L}$ and Turkish red oil (TRO) as mordant at $11.16 \mathrm{~g} / \mathrm{L}$ resulted the response of $0 \%$ on the degree of faded.

Keywords: Neem leaves, Quercetin, Natural dyes, Response surface methodology.

\section{INTRODUCTION}

There are around 10,000 kinds of synthetic dyes and pigments industries with over $7 \times 10^{5}$ tons production worldwide every year [1-3]. The use of synthetic dyes in the textile industry has been the primary cause of environmental pollution because of its undegradable properties in comparison to the natural dyes $[4,5]$. The restriction of synthetic dyes in the textile industries, actually has already made by every government concerning environmental issues and health safety consideration $[6,7]$. Natural dye has arisen as a promising substituent of synthetic dye regarding of the problems. Natural dyes have properties that could beneficially reduce the pollution caused by synthetic dyes, which have better biodegradability and less toxicity [8-11]. Natural dye often called as a green and sustainable dyeing process due to its properties, such as low toxicity, biodegradable, its abundance and eco-friendliness $[12,13]$.

Derived from natural resources, natural dyes come from plants, animals, fungi or insects extract. As derived from the natural resource, it is renewed, safe to use and environmental friendly. However, the application of natural dyes has some shortcomings. The natural dye flaws of limited colour, colouring and colouring efficiency, process complexity, natural dye sources not always present in every country [14]. Furthermore, it is less suitable for synthetic fibers because of its properties such as challenging to mix multiple dyes to produce compound shade, insufficient degree of fixation and inherent properties, limitations on the application at fabrics (usually limited to wool, natural silk fabrics, linen and cotton) [15]. Considering the potential and shortage of natural dyes, innovation is needed to reduce the shortcomings of natural dyes. Hence, Sustainable process for natural dyes extraction and its application should be designed and optimized.

Neem leaf as one of the sources of the natural dye has a great potential to be developed. The neem tree is a small tree, easily identifiable from its straight trunk, capable of reaching a height of $20 \mathrm{~m}$ which originated from Senegal, Sri Lanka, India, Malaysia, Myanmar, Pakistan, Thailand and Indonesia. Neem tree can grow in such area with less rainfall. Neem leaf extract contains quercetin compounds, which belong to the group of flavonoid. Flavonoids are natural substances that give reddish-brown dye [16]. Neem leaf extracts also have functioned

This is an open access journal, and articles are distributed under the terms of the Attribution 4.0 International (CC BY 4.0) License. This license lets others distribute, remix, tweak, and build upon your work, even commercially, as long as they credit the author for the original creation. You must give appropriate credit, provide a link to the license, and indicate if changes were made. 
as antibacterial and antifungal substances [6,17]. The utilization of neem leaf derivative product has not developed yet. With those properties, neem leaves are very promising resources to be used as natural dyes.

Natural dyes from dried neem leaves had been investigated with the type of solvent, extraction temperature, and extraction time as the independent variables [17]. Extraction of natural dyes from the neem leaves was effectively carried out at $70{ }^{\circ} \mathrm{C}$, extraction time for $1 \mathrm{~h}$, an acetone-water solvent with a ratio of $1: 1(\mathrm{v} / \mathrm{v})$ and $18 \%(\mathrm{w} / \mathrm{v})$ of leaf-solvent ratio. In addition, it was also reported that the ethanol-water mixture with a composition of 40:60 also gave good extraction results. Meanwhile, another study has been successfully performed using ultrasonic as supporting equipment to improve extraction of neem dry powder and dyeing of mordant silk fabric [18].

At the phase of dye application, the natural dye has disadvantages to add some substances to conjugate with so that the color will be more resistant to the faded $[14,16]$. Some method must be implemented during the coloring process by adding fixator and mordant. The mordanting process has been wellknown for getting new shades and good rating of fabrics [19, 20]. Adeel et al. [18] reported that biomordanting agent from herbal plants had improved the colour characteristics as compared to chemical mordants on neem natural dye.

From several studies that have been conducted, the extraction process mainly occurred using dry neem leaves which takes an extra step on the preparation. The readiness of implementation of neem leaves in a rural area should be executed. This study covers the extraction of fresh neem leaves to produce natural dyes and its application with several parameters for analyzing the optimum condition. Feed-solvent ratio, temperature, and time of extraction were used for optimizing the natural dye extraction. Meanwhile, mordant agent cost, mordant weight, and fixator weight were applied for optimizing the use of natural dye. Variable optimization process conducted using Response Surface Methodology (RSM). The responses variable for the optimization of this study were the concentration of natural dye in mother liquor and resulted the degree of faded for optimization of natural colour extraction and optimization of the application of natural dye, respectively.

\section{EXPERIMENTAL}

To differentiate with another study, fresh neem leaves were collected directly before natural dyes extraction occurred without any drying method formerly. The availability of neem trees is considerable in Indonesia without any utilization yet. The technical grade of acetone and ethanol (both $95 \%$ ) were purchased from Merck. Others substances such as alum $93 \%$, calcium carbonate $85 \%$, ferrous sulphate $99 \%$, Turkish red oil $(70 \%)$ and sodium carbonate $(99 \%)$ were procured form Sigma-Aldrich company.

General procedure: The selection of neem leaves was conducted before the harvesting process. Some requirements were the leaves approximately in the same size and colour, the stem cut in the same length and no rain recorded in the previous day. Fresh neem leaves were washed with tap-water several times and then crushed with a commercial blender. To select the suitable solvent, several solvents were used to extract natural dyes contained in neem leaves such as distilled water, acetone-distilled water 1:1 (v/v), acetone-distilled water 3:1 $(\mathrm{v} / \mathrm{v})$, ethanol-distilled water $3: 7(\mathrm{v} / \mathrm{v})$, ethanol-distilled water $7: 3$ (v/v) using the batch extractor of three-neck flash with countercurrent cooler and agitator.

Distilled water was being applied to extract the natural dyes with a further variation of independent variables. Independent variables used for the optimization process were feed solvent ratio (FSR), extraction temperature and time. The mother liquor was sampled at the prescribed minutes with a total of $10 \mathrm{~mL}$ for centrifugation. Centrifugation was carried out at a speed of $1200 \mathrm{rpm}$ for $15 \mathrm{~min}$. The number of natural dyes gained in this research was conducted using the gravimetric method from the mother liquor. The following equation describes the natural dye concentration in the extraction process:

$$
\text { Concentration }(\mathrm{g} / \mathrm{mL})=\frac{\text { Mass }_{\text {dyes }}(\mathrm{g})}{\text { Volume }_{\text {gravimetric }}(\mathrm{mL})}
$$

The dye was stored in the jerry cans for fabric dyeing application. Cloth formerly was cut in the same size $5 \mathrm{~cm} \times 5 \mathrm{~cm}$ and soaked in detergent solution $2 \mathrm{~g} / \mathrm{L}$ overnight. The cloth was washed and dried before applied in colouring process. Cloth, furthermore, was treated by mordanting with different mordant agent. Three-pieces of cloth from every mordant agent were soaked in the dye liquor. The dyed fabrics were immersed in a detergent solution $2 \mathrm{~g} / \mathrm{L}$ for $20 \mathrm{~min}$.

Detection method: There were two detection method for this study. Firstly, gravimetric method was used to analyze natural dye extracted from neem leaf. Secondly, Vernier SpectroVis Plus Spectrophotometer (SVIS-PL) was used to measure the absorbance of the degree of faded in natural dyes application process. The degree of faded was calculated using the following equation:

$$
\text { Degree of faded }(\%)=\left|\frac{\mathrm{A}^{\prime}-\mathrm{A}}{\mathrm{A}}\right| \times 100
$$

where, $A^{\prime}=$ absorbance of detergent solution after the faded test; $\mathrm{A}=$ absorbance of detergent solution before the faded test.

Data analysis: The purpose of this study is to optimize several variables which give effect in the extraction process and natural dyes application. Determination of optimization on several variables was carried out by using response surface methodology (RSM) in Minitab ${ }^{\circledR}$ program. Response surface methodology was chosen because it can reduce the number of the experiment for evaluating the variables and their interactions [21-26]. A three-level factorial design was used for every optimization process. The dependent variables in this study were the yield of colour extraction and degree of faded for optimization of natural colour extraction and optimization of the application of natural dye, respectively. The detailed independent variables are listed in Table-1.

A non-linear polynomial equation was used to correlate the variables, in which the responses as dependent variables and the factor as the independent variable. The equation has a prevalent form $[21,23,25]$, which written as follows:

$$
Y=\beta_{o}+\sum_{i-1}^{k} \beta_{i} x_{i}+\sum_{i-1}^{k} \beta_{i i} x_{i i}^{2}+\sum_{1<i \leq j}^{k} \beta_{i j} x_{i} x_{j}+\varepsilon
$$

where $Y$ is the response; $\beta_{\mathrm{o}}$ is the constant coefficient, $\beta_{\mathrm{i}}, \beta_{\mathrm{ii}}$ and $\beta_{\mathrm{ij}}$ are the coefficients for linear, quadratic and interaction 


\begin{tabular}{clccc}
\hline \multicolumn{4}{c}{ TABLE-1 } \\
& $\begin{array}{c}\text { RXPERIMENTAL DESIGN AND LEVEL } \\
\text { OF INDEPENDENT VARIABLES }\end{array}$ \\
\cline { 3 - 5 } & \multirow{2}{*}{ Independent variable } & +1 & 0 & -1 \\
\hline \multirow{2}{*}{ Dyes } & FSR $(\% \mathrm{w} / \mathrm{v})$ & 20 & 35 & 50 \\
extraction & Temperature $\left({ }^{\circ} \mathrm{C}\right)$ & 60 & 70 & 80 \\
& Time $(\mathrm{min})$ & 40 & 60 & 80 \\
\hline \multirow{2}{*}{ Dyes } & Fixator cost $(\$ / \mathrm{kg})$ & 1 & 2 & 5 \\
application & Fixator concentration $(\mathrm{g} / \mathrm{L})$ & 5 & 10 & 15 \\
& Mordant concentration, TRO $(\mathrm{g} / \mathrm{L})$ & 5 & 10 & 15 \\
\hline
\end{tabular}

effect, respectively; $\mathrm{x}_{\mathrm{i}}$ and $\mathrm{x}_{\mathrm{j}}$ are the factors ( $\mathrm{i}$ and $\mathrm{j}$ are the range from 1 to $\mathrm{k}$ ); and $\varepsilon$ describes the error. The proposed model was examined using the coefficient of determination $\left(\mathrm{R}^{2}\right)$ to contrast the thoroughness. The value of $\mathrm{R}^{2}$ is in the range from 0 to 1 . The bigger the value of $\mathrm{R}^{2}$ the better the model [27].

\section{RESULTS AND DISCUSSION}

Solvent selection: Solvent selection should be made before conducting further research. Several solvents were used as shown in Table-2. Based on Table 2, it can be concluded that water-acetone was the best solvent. Meanwhile, water-ethanol gave similar trend with water solvent. This is due to acetone acts as a non-hydrogen-bond donating solvent which is also called non-HBD that contains double carbon bonds with oxygen or nitrogen. Ethanol is a hydrogen bond called HBD where the solvent has the polarity of dipole bond of O-H bond, which has a large electronegativity difference from hydrogen and oxygen atoms. Even though water has the greatest electrification between acetone and ethanol, from the demonstration results, water has the smallest concentration value because of the strong hydrogen bond formation between water and neem extract. The concentration generally increases with the presence of acetone and ethanol as solvent.

The results showed that the distilled water is quite good to be used as a solvent compared to others. Distilled water was being used for the optimization process for its eco-friendly solvent. Furthermore, the individual concentration of mother liquor was calculated as the representative number for the extraction process. The variation is believed caused by not uniformly natural dye content in the raw material. For further industrial process, fresh leaves selection process should overcome these issues with the determined standard operational procedure.

Effect of operating condition on extraction process based on statistical analysis: The number of natural dyes extracted from neem leaves was analyzed by gravimetric method. The measured weight was processed (eqn. 1) to obtain experimental concentration. The response variable, concentration, was being processed with Minitab ${ }^{\circledR}$ software using response surface methodology (RSM). The value of FSR, temperature and time respectively represent $\mathrm{X}_{1}, \mathrm{X}_{2}$ and $\mathrm{X}_{3}$, while experimental yield represents $Y$. The predicted concentration is shown in Table-3 as an output response from the software calculation. It seems that the modeling is sufficiently correlated with the experimental data. The empirical relationship between the response (concentration) and the independent variables $\left(\mathrm{X}_{1}\right.$, $\mathrm{X}_{2}$ and $\mathrm{X}_{3}$ ) has been expressed by the second-order polynomial equation as:

$$
\begin{aligned}
& \text { Concentration }=19.2-0.672 \mathrm{X}_{1}+0.61 \mathrm{X}_{2}-0.585 \mathrm{X}_{3}- \\
& 0.00399 \mathrm{X}_{1}^{2}-0.00854 \mathrm{X}_{2}^{2}+0.00142 \mathrm{X}_{3}^{2}+0.01739 \mathrm{X}_{1} \mathrm{X}_{2} \\
& +0.00594 \mathrm{X}_{1} \mathrm{X}_{3}+0.00330 \mathrm{X}_{2} \mathrm{X}_{3}
\end{aligned}
$$

\begin{tabular}{|c|c|c|c|c|c|}
\hline \multicolumn{6}{|c|}{$\begin{array}{c}\text { TABLE-3 } \\
\text { CONCENTRATION'S RESPONSE COMPARED } \\
\text { TO THE EXPERIMENTAL RESULT }\end{array}$} \\
\hline \multirow{2}{*}{ No. } & \multirow{2}{*}{$\begin{array}{c}\text { FSR (\%) } \\
\mathrm{X}_{1}\end{array}$} & \multirow{2}{*}{$\begin{array}{c}\text { Temp. }\left({ }^{\circ} \mathrm{C}\right) \\
\mathrm{X}_{2}\end{array}$} & \multirow{2}{*}{$\begin{array}{c}\text { Time (min) } \\
\mathrm{X}_{3}\end{array}$} & \multicolumn{2}{|c|}{ Concentration $(\mathrm{g} / \mathrm{L})$} \\
\hline & & & & Exp. & Pred. \\
\hline 1 & 20 & 60 & 40 & 22.13 & 22.19 \\
\hline 2 & 20 & 60 & 60 & 21.43 & 19.67 \\
\hline 3 & 20 & 60 & 80 & 20.32 & 18.28 \\
\hline 4 & 20 & 70 & 40 & 21.62 & 21.95 \\
\hline 5 & 20 & 70 & 60 & 16.52 & 20.09 \\
\hline 6 & 20 & 70 & 80 & 18.25 & 19.36 \\
\hline 7 & 20 & 80 & 40 & 21.13 & 20.00 \\
\hline 8 & 20 & 80 & 60 & 19.65 & 18.80 \\
\hline 9 & 20 & 80 & 80 & 18.00 & 18.73 \\
\hline 10 & 35 & 60 & 40 & 25.00 & 28.04 \\
\hline 11 & 35 & 60 & 60 & 28.42 & 27.29 \\
\hline 12 & 35 & 60 & 80 & 26.44 & 27.69 \\
\hline 13 & 35 & 70 & 40 & 32.46 & 30.40 \\
\hline 14 & 35 & 70 & 60 & 29.52 & 30.32 \\
\hline 15 & 35 & 70 & 80 & 31.46 & 31.38 \\
\hline 16 & 35 & 80 & 40 & 31.26 & 31.06 \\
\hline 17 & 35 & 80 & 60 & 31.79 & 31.64 \\
\hline 18 & 35 & 80 & 80 & 34.83 & 33.36 \\
\hline 19 & 50 & 60 & 40 & 34.33 & 32.09 \\
\hline 20 & 50 & 60 & 60 & 31.14 & 33.13 \\
\hline 21 & 50 & 60 & 80 & 34.45 & 35.30 \\
\hline 22 & 50 & 70 & 40 & 37.14 & 37.06 \\
\hline 23 & 50 & 70 & 60 & 41.09 & 38.76 \\
\hline 24 & 50 & 70 & 80 & 42.86 & 41.60 \\
\hline 25 & 50 & 80 & 40 & 38.05 & 40.33 \\
\hline 26 & 50 & 80 & 60 & 42.82 & 42.69 \\
\hline 27 & 50 & 80 & 80 & 45.27 & 46.19 \\
\hline
\end{tabular}

For further analysis, the comparison of experimental and predicted concentration from the model is presented in Fig. 1a. It can be shown from Fig. 1a that the data remains tightly on the reference line. Standardized residual is also shown in Fig. 1b. It concludes that the data are normally distributed, as

TABLE-2

CONCENTRATION OF NATURAL DYES USING SEVERAL SOLVENTS

\begin{tabular}{ccccccc}
\hline Solvent & \multicolumn{5}{c}{ Concentration of natural dyes $(\mathrm{g} / \mathrm{L})$} \\
\cline { 2 - 6 } & $10 \mathrm{~min}$ & $20 \mathrm{~min}$ & $30 \mathrm{~min}$ & $50 \mathrm{~min}$ & $70 \mathrm{~min}$ & $90 \mathrm{~min}$ \\
\hline Distilled water & 14.90 & 15.05 & 15.95 & 15.05 & 18.00 & 15.15 \\
Water-acetone (1:1) & 21.10 & 23.50 & 23.15 & 25.55 & 25.15 & 24.05 \\
Water-acetone (1:3) & 22.20 & 23.75 & 25.95 & 26.55 & 27.40 & 28.70 \\
Water-ethanol (7:3) & 16.75 & 17.65 & 16.90 & 18.90 & 15.80 & 17.80 \\
Water-ethanol (3:7) & 14.60 & 15.35 & 15.90 & 14.95 & 15.90 \\
\hline
\end{tabular}



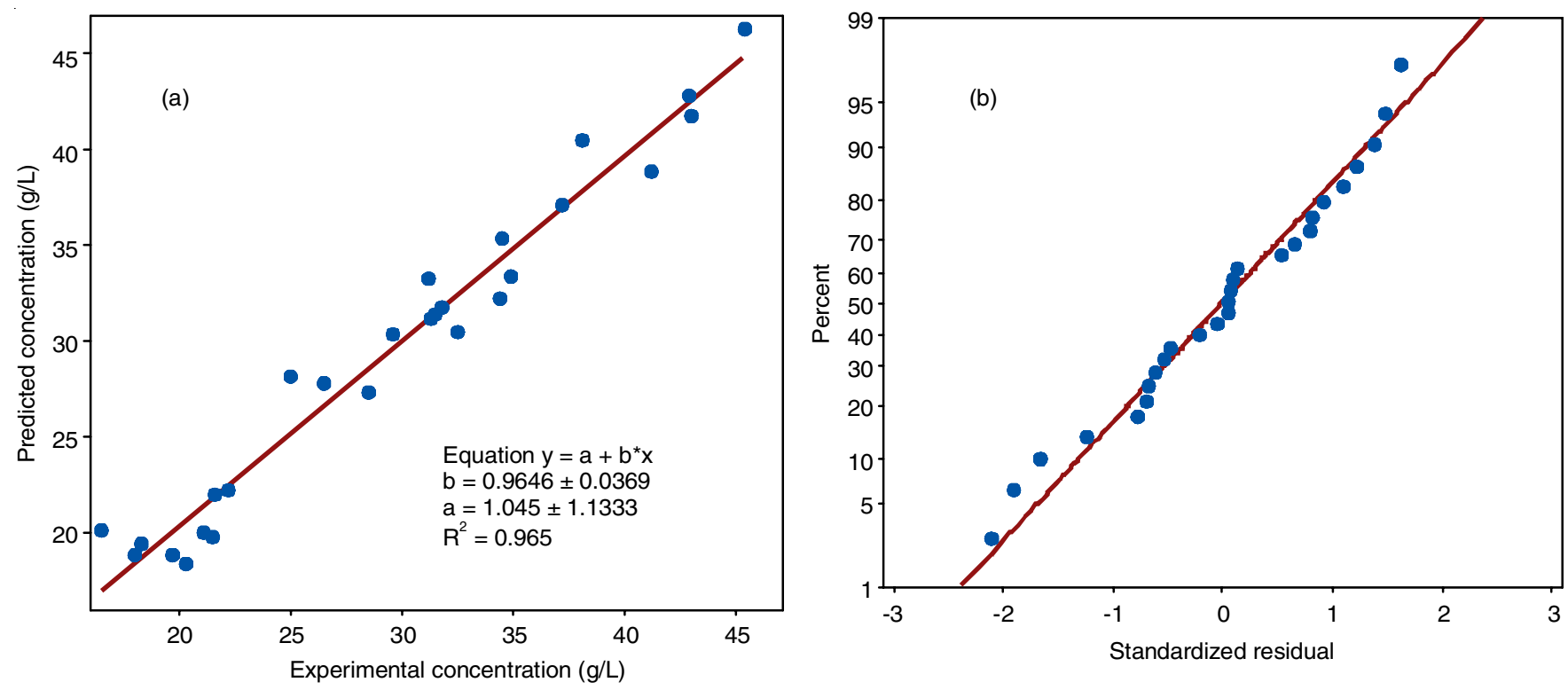

Fig. 1. Standardized residual (a) and linear fitting plot (b) for natural dyes extraction

seen in Fig. 1b. It is because the data are closed to the reference line with fewer outlier data. The smaller residual value gives higher accuracy of model [22,28].

The obtained model, was performed by ANOVA to check the adequacy and fitness of the model. ANOVA is one of statistical techniques which test the correlation and significance of the research parameters $[23,29]$. The output of F-value and P-value were used with the level 0.05 as the assessment tools to predict the significance of the parameter used in the research. The results of ANOVA analysis are presented in Table-4. The higher the F-value compared to F-table, the better the model is. Reversibly, the lower the P-value results in the better model. The model shows that the F-value is 51.52 with 3.05 F-table and $\mathrm{P}$-value is below 0.001, which means that the appropriate model is produced because of statistically significance. On the other hand, feed-solvent ratio (FSR) and temperature of extraction are the significant factor for the extraction process because the $\mathrm{P}$-value is below 0.001 , while extraction time does not comply the significance although the value of P-value is still relatively small. Furthermore, the high value of $\mathrm{R}^{2}, 96.56 \%$, describes that the model is appropriate for this study.

The effect of each parameter is presented in Fig. 2. It can be concluded that all variables give similar tendency for the increasing of concentration obtained. The increasing of variables

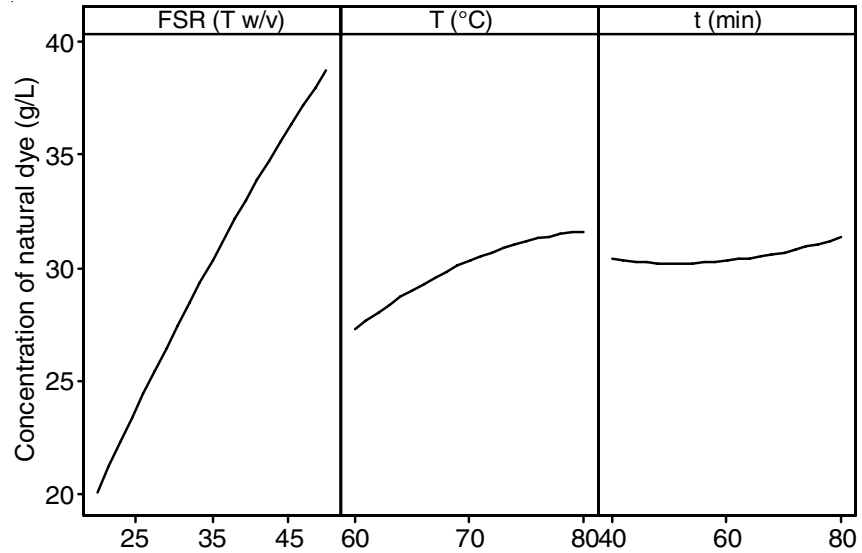

Fig. 2. Factorial plot of each parameter for the natural dyes extraction process

affect the concentration became higher although the value is not similar to each other. The variation of FSR produces a linear line with a high gradient which has a high impact to the obtained concentration. Meanwhile, temperature and duration time do not too impactful proved with a low gradient. With the suitable predictive model, the production of natural dye from neem leaves can be so precise. The application of natural dyes is still in direct use of mother liquor produced from the extraction process in the colouring process. The strength of natural dye

TABLE-4

OUTPUT OF ANOVA ANALYSIS FOR THE RESEARCH MODEL OF THE DYES EXTRACTION PROCESS

\begin{tabular}{|c|c|c|c|c|c|c|c|}
\hline Source & Coefficient & $\begin{array}{c}\text { Standard error } \\
\text { coefficient }\end{array}$ & $\mathrm{DF}$ & $\begin{array}{c}\text { Adj. sum of } \\
\text { square }\end{array}$ & $\begin{array}{c}\text { Adj. mean of } \\
\text { square }\end{array}$ & F-value & P-value \\
\hline Model & 30.32 & 1.00 & 9.00 & 1795.49 & 199.50 & 51.52 & $<0.001$ \\
\hline FSR, $X_{1}$ & 9.34 & 0.46 & 1.00 & 1570.01 & 1570.01 & 405.44 & $<0.001$ \\
\hline $\mathrm{T}, \mathrm{X}_{2}$ & 2.17 & 0.46 & 1.00 & 85.06 & 85.06 & 21.97 & $<0.001$ \\
\hline $\mathrm{t}, \mathrm{X}_{3}$ & 0.49 & 0.46 & 1.00 & 4.27 & 4.27 & 1.10 & 0.308 \\
\hline FSR $*$ FSR & -0.90 & 0.80 & 1.00 & 4.83 & 4.83 & 1.25 & 0.280 \\
\hline $\mathrm{T}^{*} \mathrm{~T}$ & -0.85 & 0.80 & 1.00 & 4.38 & 4.38 & 1.13 & 0.303 \\
\hline$t^{*} \mathrm{t}$ & 0.57 & 0.80 & 1.00 & 1.93 & 1.93 & 0.50 & 0.489 \\
\hline FSR*T & 2.61 & 0.57 & 1.00 & 81.67 & 81.67 & 21.09 & $<0.001$ \\
\hline $\mathrm{FSR}^{*} \mathrm{t}$ & 1.78 & 0.57 & 1.00 & 38.10 & 38.10 & 9.84 & 0.006 \\
\hline $\mathrm{T}^{*} \mathrm{t}$ & 0.66 & 0.57 & 1.00 & 5.23 & 5.23 & 1.35 & 0.261 \\
\hline $\mathrm{R}^{2}$ & $96.46 \%$ & & & & & & \\
\hline
\end{tabular}


can be described with the concentration of mother liquor so that similar condition of colouring process can be applied.

Effect of operating parameters in extracted natural dye application: Originally, the independent variables for application of natural dyes were fixator agent (alum, lime and $\mathrm{FeSO}_{4}$ ), fixator concentration and Turkish red oil (TRO) concentration $(\mathrm{g} / \mathrm{L})$ as the mordant agent. Because of the difficulties to process the fixator agent parameter, we converted the parameter to the cost of each fixator agent, so it produced the same measurable value. It looks reasonable to optimize the process of natural dyes application due to the expense spent while using different fixator agent. The experimental degree of faded dye was produced by comparing the initial condition absorbance with the final condition absorbance after the cloth immersion process in detergent solution was occurred. The higher the degree of faded degree, the less effective fixator agent to prevent color for faded is. The absorbance was measured by Vernier SpectroVis Plus Spectrophotometer (SVIS-PL) at $395.5 \mathrm{~nm}$ wavelength. As well-known, the absorbance describes the concentration in solution which means that can further describe the degree of faded. The value of fixator cost $(\$ / \mathrm{kg})$, fixator concentration $(\mathrm{g} / \mathrm{L})$, and TRO concentration $(\mathrm{g} / \mathrm{L})$ as mordant agent, respectively represent $X_{1}, X_{2}$ and $X_{3}$, while the experimental degree of faded represents $\mathrm{Y}$. Variable gained from the research was being processed with Minitab ${ }^{\circledast}$ software using RSM. The predicted degree of faded is shown in Table-5 as an output response from the software calculation.

It seems that the modeling is sufficiently correlated with the experimental data. The empirical relationship between the response (degree of faded) and the independent variables $\left(\mathrm{X}_{1}\right.$, $\mathrm{X}_{2}$ and $\mathrm{X}_{3}$ ) has been expressed by the second-order polynomial equation as:

$$
\begin{aligned}
& \text { Yield }=305-112.5 \mathrm{X}_{1}-30.2 \mathrm{X}_{2}-20.1 \mathrm{X}_{3}+8.6 \mathrm{X}_{1}^{2}+ \\
& 0.5191 \mathrm{X}_{2}^{2}+0.869 \mathrm{X}_{3}^{2}+15.48 \mathrm{X}_{1} \mathrm{X}_{2}+1.25 \mathrm{X}_{1} \mathrm{X}_{3}- \\
& 0.042 \mathrm{X}_{2} \mathrm{X}_{3}
\end{aligned}
$$

The P-value is used to predict the significance of each parameter and parameter correlation. The value of ANOVA result for application of natural dyes could be seen in Table- 6 . It shows that the significance of the model is high because of its $\mathrm{P}$-value $(\mathrm{P}<0.001)$. It concludes that the calculated model is suitable for the application of natural dyes process. The significance occurred for the parameter such as mordant cost and

\begin{tabular}{|c|c|c|c|c|c|}
\hline \multicolumn{6}{|c|}{$\begin{array}{c}\text { TABLE-5 } \\
\text { DEGREE OF FADED RESPONSE COMPARED } \\
\text { TO THE EXPERIMENTAL RESULT }\end{array}$} \\
\hline \multirow{2}{*}{ No. } & \multirow{2}{*}{$\begin{array}{c}\text { Fixator cost } \\
(\$ / \mathrm{kg}) \\
\mathrm{X}_{1}\end{array}$} & \multirow{2}{*}{$\begin{array}{c}\text { Fixator } \\
\text { conc. }(\mathrm{g} / \mathrm{L}) \\
\mathrm{X}_{2} \\
\end{array}$} & \multirow{2}{*}{$\begin{array}{c}\text { TRO } \\
(\mathrm{g} / \mathrm{L}) \\
\mathrm{X}_{3}\end{array}$} & \multicolumn{2}{|c|}{ Degree of faded $(\%)$} \\
\hline & & & & Exp. & Pred. \\
\hline 1 & 1.0329 & 5.0014 & 5.0004 & 9.3203 & 66.6514 \\
\hline 2 & 1.0329 & 10.0012 & 5.0004 & 2.2088 & 33.5144 \\
\hline 3 & 1.0329 & 15.0018 & 5.0004 & 41.5234 & 26.3342 \\
\hline 4 & 1.7215 & 5.0008 & 5.0004 & 104.1477 & 63.0517 \\
\hline 5 & 1.7215 & 10.0008 & 5.0004 & 101.6666 & 83.2198 \\
\hline 6 & 1.7215 & 15.0006 & 5.0004 & 96.5590 & 129.3436 \\
\hline 7 & 4.8201 & 5.0006 & 5.0004 & 125.4773 & 147.2416 \\
\hline 8 & 4.8201 & 10.0002 & 5.0004 & 439.1283 & 407.2779 \\
\hline 9 & 4.8201 & 15.0008 & 5.0004 & 729.9310 & 693.3278 \\
\hline 10 & 1.0329 & 5.0002 & 10.0001 & 30.2082 & 36.7311 \\
\hline 11 & 1.0329 & 10.0008 & 10.0001 & 54.8501 & 2.5399 \\
\hline 12 & 1.0329 & 15.0002 & 10.0001 & 32.2439 & -5.6882 \\
\hline 13 & 1.7215 & 5.0006 & 10.0001 & 58.5033 & 37.4362 \\
\hline 14 & 1.7215 & 10.0004 & 10.0001 & 117.5593 & 56.5574 \\
\hline 15 & 1.7215 & 15.0003 & 10.0001 & 43.2586 & 101.6358 \\
\hline 16 & 4.8201 & 5.0002 & 10.0001 & 182.9223 & 141.0297 \\
\hline 17 & 4.8201 & 10.0014 & 10.0001 & 287.8868 & 400.1065 \\
\hline 18 & 4.8201 & 15.0014 & 10.0001 & 647.9981 & 685.0823 \\
\hline 19 & 1.0329 & 5.0012 & 15.0003 & 13.9509 & 50.2550 \\
\hline 20 & 1.0329 & 10.0002 & 15.0003 & 27.2603 & 15.0313 \\
\hline 21 & 1.0329 & 15.0014 & 15.0003 & 19.5600 & 5.7569 \\
\hline 22 & 1.7215 & 5.0004 & 15.0003 & 57.1403 & 55.2861 \\
\hline 23 & 1.7215 & 10.0008 & 15.0003 & 70.0716 & 73.3654 \\
\hline 24 & 1.7215 & 15.0016 & 15.0003 & 68.4009 & 117.4114 \\
\hline 25 & 4.8201 & 5.0006 & 15.0003 & 194.3024 & 178.3245 \\
\hline 26 & 4.8201 & 10.0004 & 15.0003 & 407.2947 & 436.2826 \\
\hline 27 & 4.8201 & 15.0012 & 15.0003 & 793.9880 & 720.2560 \\
\hline
\end{tabular}
concentration. Furthermore, the interaction of mordant cost and concentration also gives statistical significance to the calcu- lated model $(\mathrm{P}<0.001)$. Another parameter and parameter interaction do not satisfy the significance through the calculated model. The value of $\mathrm{R}^{2}$ also supports the significance of the calculated model, $96.39 \%$. It concludes that the model is acceptable to be used for the natural dyes application.

The standardized residual and linear plotting had already made to depict the acceptance of the proposed model. It seems that the results in Fig. 3a fitted near the reference line which means smaller residual occurred. Smaller residual value gives higher accuracy of the model $[22,24,28]$. The linear plotting of experimental and predicted yield (Fig. 3b) is also shown that the data appropriately fitted with the regression line.

The effect of each parameter for natural dyes application is shown in Fig. 4. It can be concluded that the higher the cost

\begin{tabular}{|c|c|c|c|c|c|c|c|}
\hline Source & Coefficient & $\begin{array}{c}\text { Standard error } \\
\text { coefficient }\end{array}$ & DF & $\begin{array}{l}\text { Adj. sum of } \\
\text { square }\end{array}$ & $\begin{array}{l}\text { Adj. mean of } \\
\text { square }\end{array}$ & F-value & $\mathrm{P}$-value \\
\hline Model & 170.6 & 39.7 & 9 & 1295459 & 143940 & 50.4 & $<0.001$ \\
\hline Cost, $\mathrm{X}_{1}$ & 198.8 & 12.6 & 1 & 711196 & 711196 & 249.03 & $<0.001$ \\
\hline Conc., $\mathrm{X}_{2}$ & 125.4 & 13 & 1 & 267167 & 267167 & 93.55 & $<0.001$ \\
\hline $\mathrm{TRO}, \mathrm{X}_{3}$ & 2.6 & 13 & 1 & 117 & 117 & 0.04 & 0.842 \\
\hline Cost*Cost & 30.7 & 39.1 & 1 & 1762 & 1762 & 0.62 & 0.443 \\
\hline Conc. *Conc. & 13 & 21.8 & 1 & 1011 & 1011 & 0.35 & 0.56 \\
\hline TRO*TRO & 21.7 & 21.8 & 1 & 2834 & 2834 & 0.99 & 0.333 \\
\hline Cost*Conc. & 146.6 & 14.5 & 1 & 292741 & 292741 & 102.5 & $<0.001$ \\
\hline Cost*TRO & 11.9 & 14.5 & 1 & 1919 & 1919 & 0.67 & 0.424 \\
\hline Conc.*TRO & -1 & 15.4 & 1 & 13 & 13 & 0 & 0.947 \\
\hline$R^{2}$ & $96.39 \%$ & & & & & & \\
\hline
\end{tabular}

TABLE-6

OUTPUT OF ANOVA ANALYSIS FOR THE RESEARCH MODEL OF NATURAL DYES APPLICATION 

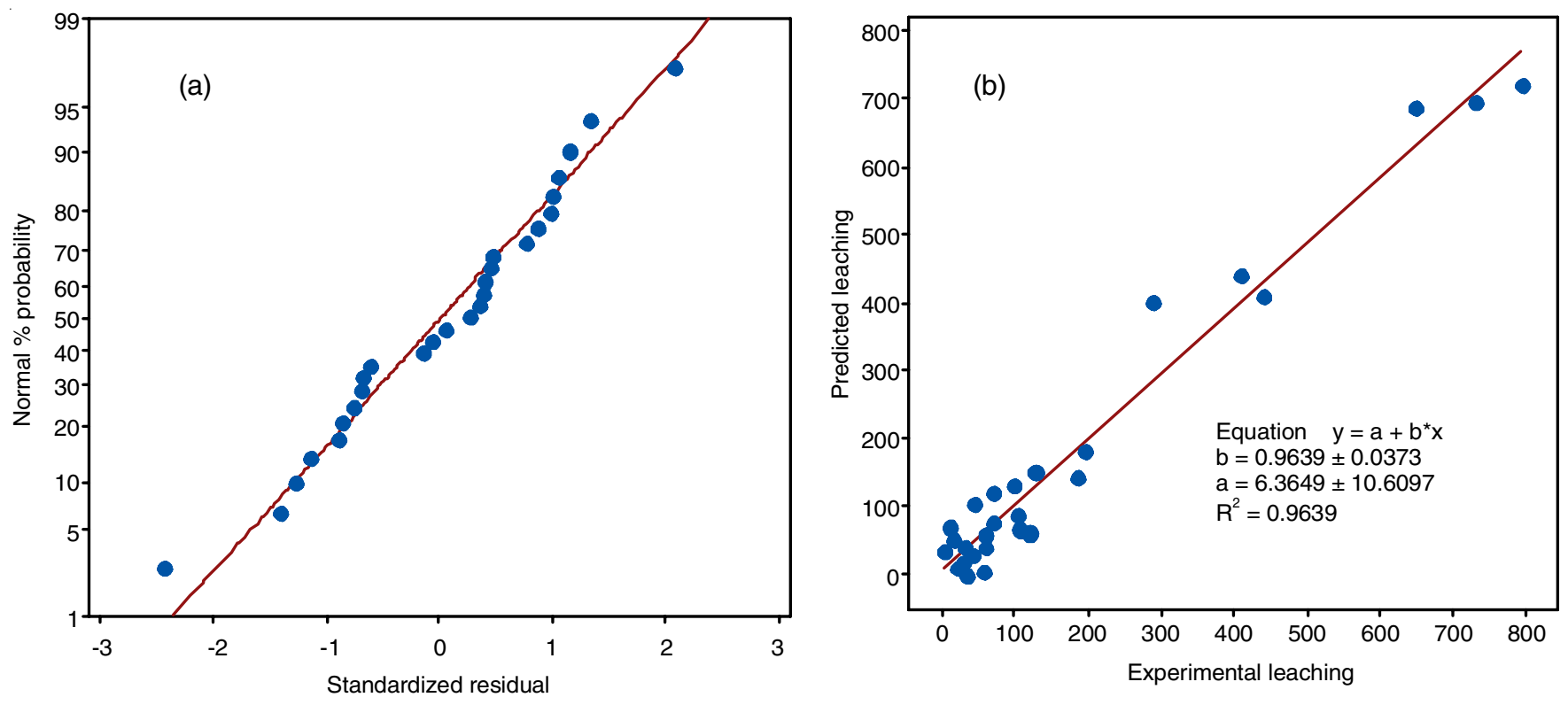

Fig. 3. Standardized residual and linear fitting plot for application of natural dyes

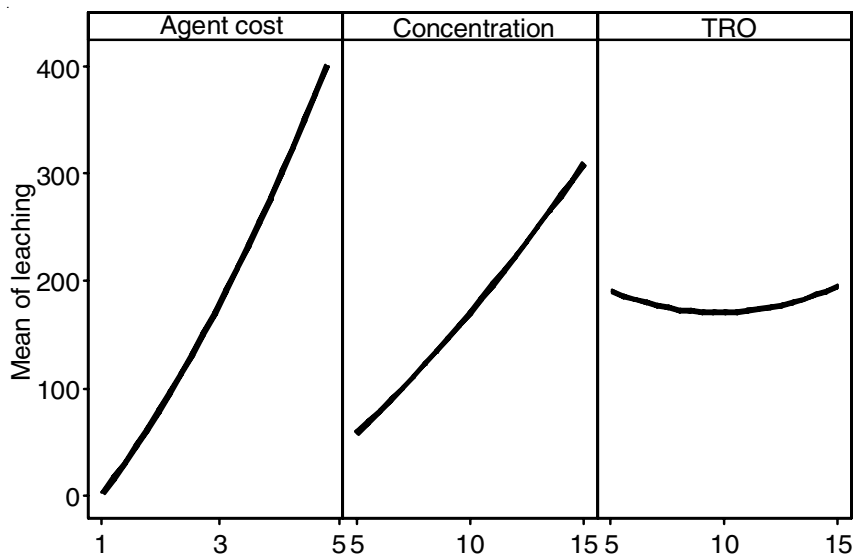

Fig. 4. Factorial plot of each parameter for natural dyes application

of mordant agent the higher degree of faded produced. It is mainly because of the properties of the mordant agent which affects the colouring process. Alum which represents the lowest mordant agent price gives an optimum condition for colouring process because it could keep the colour from fade. It gives a double impact on the optimization of natural dyes application because of its cost and its properties. Concentration gives the same trend with mordant agent cost. Meanwhile, TRO concentration gives vagueness because it gives quadratic line instead of the linear line.

Assesment of optimum condition using RSM: The correlation of each variable for optimization analysis can be seen in Fig. 5. Fig. 5a shows calculated concentration as a dependent variable against independent variables in the extraction process, while Fig. 5b shows calculated degree of faded value as a dependent variable in natural dyes application process against fixator unit cost, fixator concentration and TRO concentration. For those each independent variables, optimization analysis was conducted to find the desired parameter for extraction process and natural dyes application.

The optimum condition analysis for the extraction process and application process of natural dyes from neem leaves were evaluated using RSM Minitab ${ }^{\circledR}$. The output is presented in Table-7. The extraction process of natural dyes from neem leaves is expected to gain a higher concentration. Higher concentration generates higher natural dyes extracted from neem leaves. As a consequence, concentration response should be in maximum condition with the independent variable variance. Differ with the extraction process of natural dyes from neem leaves, application process of natural dyes from neem leaves is supposed to have less degree of faded outcome from the independent variable variance. It is mainly because the higher the degree of faded value, the less effective mordant agent and fixator to keep the colour of cloth. Furthermore, degree of faded response should be in minimum condition.

TABLE-7

OPTIMIZATION OUTPUT OF MINITAB® SOFTWARE FOR THE EXTRACTION PROCESS AND APPLICATION PROCESS OF NATURAL DYES FROM NEEM LEAVES

\begin{tabular}{cc|cc}
\hline \multicolumn{2}{c|}{$\begin{array}{c}\text { Extraction process of } \\
\text { natural dyes }\end{array}$} & \multicolumn{2}{c}{$\begin{array}{c}\text { Application process of } \\
\text { natural dyes }\end{array}$} \\
\hline Variable & Value & Variable & Value \\
FSR $(\% \mathrm{w} / \mathrm{v})$ & 50 & Fixator cost $(\$ / \mathrm{kg})$ & 1.033 \\
$\mathrm{~T}\left({ }^{\circ} \mathrm{C}\right)$ & 80 & Fixator conc. $(\mathrm{g} / \mathrm{L})$ & 14.09 \\
$\mathrm{t}(\mathrm{min})$ & 80 & TRO conc. $(\mathrm{g} / \mathrm{L})$ & 11.16 \\
Conc. $(\mathrm{g} / \mathrm{L})$ & 46.19 & Degree of faded $(\%)$ & 0 \\
\hline \multicolumn{2}{c}{} \\
\hline
\end{tabular}

The outcome of the optimization process for the extraction process and application process of natural dyes from neem leaves is very useful to predict further research of neem leaves extraction and application. It can either reduce significance variable to be used in the further research or can optimize present parameter to produce prospective process. From Table-7, it is concluded that the optimum process for extraction process of natural dyes from neem leaves produces a concentration of $46.19 \mathrm{~g} / \mathrm{L}$ with the parameter condition $50 \% \mathrm{w} / \mathrm{v}$ feed-solvent ratio, the temperature of $80^{\circ} \mathrm{C}$ and extraction duration of 80 min. Otherwise, the optimum process for application process of natural dyes from neem leaves obtains the faded degree of 

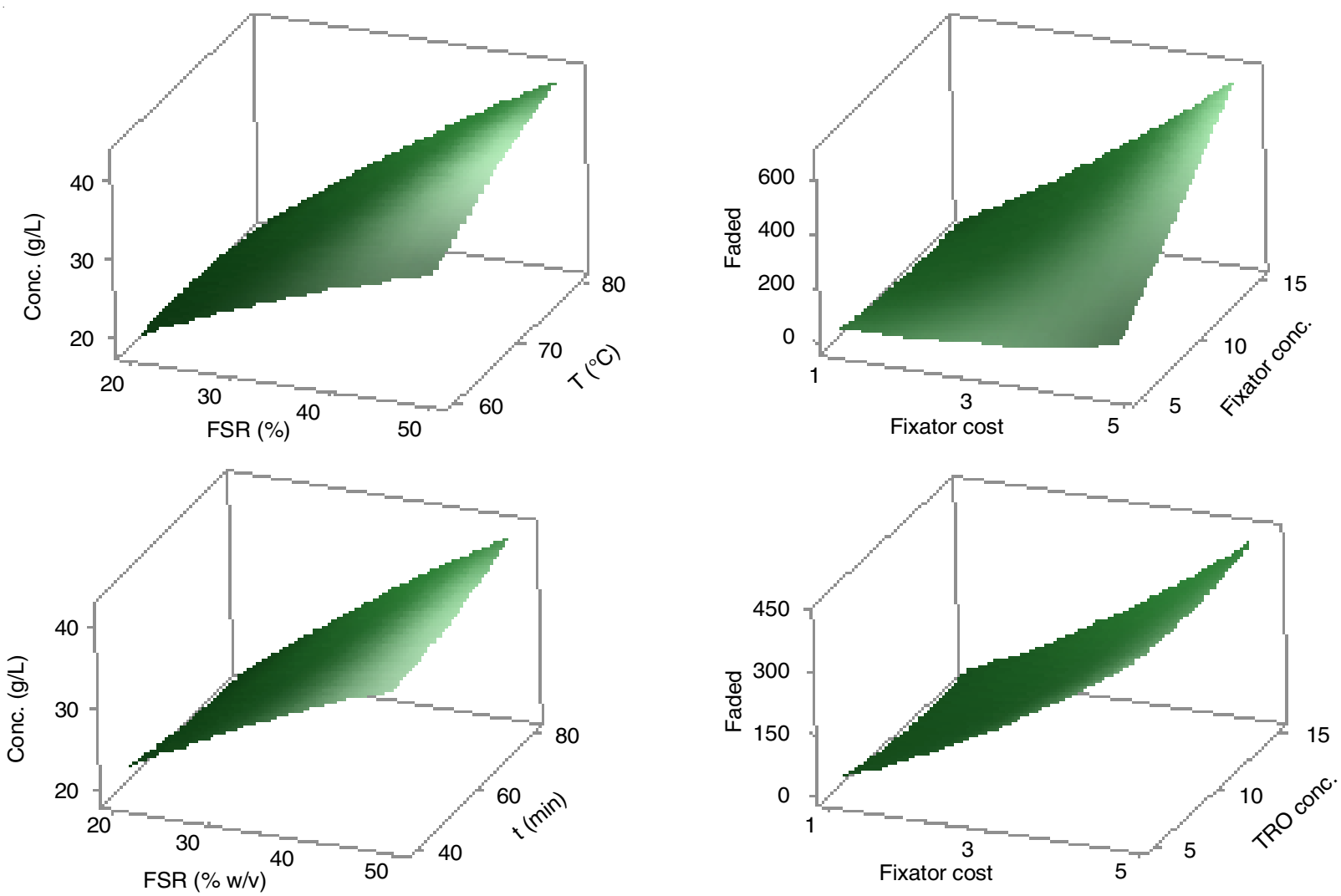

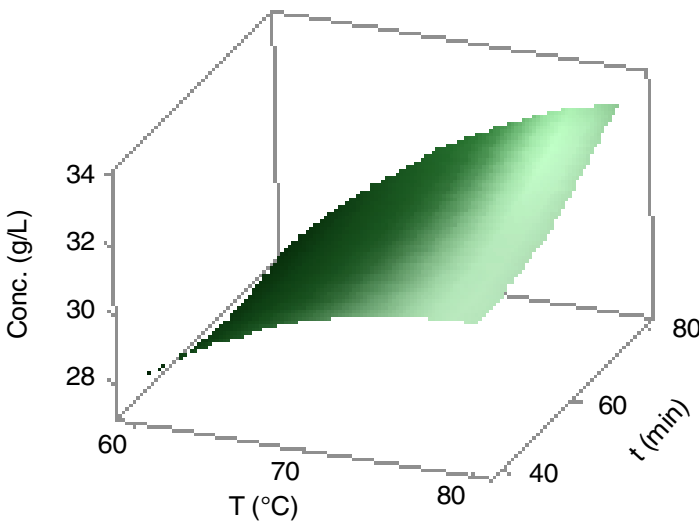

(a)

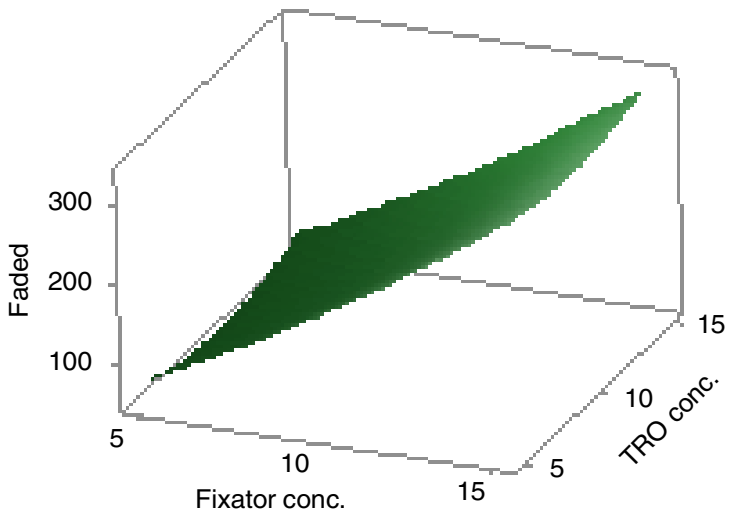

(b)

Fig. 5. Contour plot of variables relationship; (a) extraction process and (b) application process

$0 \%$ with the parameter condition agent cost $\$ 1.033$; which is an alum, fixator agent concentration of $14.09 \mathrm{~g} / \mathrm{L}$, and TRO concentration as a mordant agent of $11.16 \mathrm{~g} / \mathrm{L}$.

\section{Conclusion}

Three-level response surface design is reliable and very effective for optimizing extraction process and application process parameters of natural dyes from neem leaves. It briefly gives correlation and interaction of that parameter in every optimization process. Feed-solvent ratio (FSR) and temperature took the great part for the extraction process followed by the temperature of extraction because of its significance. The calculated model could well represent the independent variable to calculate the dependent variable of the concentration of mother liquor from the extraction process. It proved by the greater value of $\mathrm{R}^{2}(96.46 \%)$. This model can predict the desirable concentration of natural dyes produced from neem leaves. Fixator cost and concentration had a great effect on the application of natural dyes from neem leaves because of its $\mathrm{P}$-value $(\mathrm{P}<0.001)$. The value of $\mathrm{R}^{2}$ also supports the significance of the calculated model $(96.39 \%)$. It is very acceptable to be used for the natural dyes application. The optimum process for extraction process of natural dyes from neem leaves produces concentration $46.19 \mathrm{~g} / \mathrm{L}$ with the parameter condition $50 \% \mathrm{w} / \mathrm{v} \mathrm{FSR} 80^{\circ} \mathrm{C}$ and extraction duration of $80 \mathrm{~min}$. Otherwise, the optimum process for application process of natural dyes from neem leaves obtains the faded degree of $0 \%$ with the parameter condition fixator agent cost $\$ 1.033$; which is an alum, fixator agent concentration of $14.09 \mathrm{~g} / \mathrm{L}$ and TRO concentration as mordant of $11.16 \mathrm{~g} / \mathrm{L}$. 


\section{ACKNOWLEDGEMENTS}

This study was supported and facilitated by Department of Chemical Engineering, Universitas Gadjah Mada, Yogyakarta, Indonesia.

\section{CONFLICT OF INTEREST}

The authors declare that there is no conflict of interests regarding the publication of this article.

\section{REFERENCES}

1. C.J. Ogugbue and T. Sawidis, Biotechnol. Res. Int., 2011, Article ID 967925 (2011);

https://doi.org/10.4061/2011/967925.

2. T. Robinson, G. McMullan, R. Marchant and P. Nigam, Bioresour. Technol., 77, 247 (2001);

https://doi.org/10.1016/S0960-8524(00)00080-8.

3. H. Zollinger, Properties of Organic Dyes and Pigments in Color Chemistry, VCH Publishers: New York (1978).

4. K. El-Nagar, S.H. Sanad, A.S. Mohamed and A. Ramadan, Polym. Plast. Technol. Eng., 44, 1269 (2005); https://doi.org/10.1080/03602550500207816.

5. M.J. Iqbal and M.N. Ashiq, J. Hazard. Mater., 139, 57 (2007); https://doi.org/10.1016/j.jhazmat.2006.06.007.

6. M. Parvinzadeh Gashti, B. Katozian, M. Shaver and A. Kiumarsi, Color. Technol., 130, 54 (2014); https://doi.org/10.1111/cote.12065.

7. A. Kiumarsi, M. Parvinzadeh Gashti, P. Salehi and M. Dayeni, J. Textil. Inst., 108, 66 (2017); https://doi.org/10.1080/00405000.2016.1153865.

8. M. Alam, M. Rahman and M. Haque, Bangladesh J. Sci. Ind. Res., 42, 217 (1970); https://doi.org/10.3329/bjsir.v42i2.475.

9. T. Bechtold, A.M. Ali, E. Ganglberger and S. Geissler, Int. J. Environ. Waste Manag., 2, 215 (2008); https://doi.org/10.1504/IJEWM.2008.018244.

10. B. Chengaiah, K.M. Rao, K.M. Kumar, M. Alagusundaram and C.M. Chetty, Int. J. Pharm. Technol. Res., 2, 144 (2010).

11. F. Giacomini, M.A.B. Menegazzo, J.C.O. dos Santos, P.A. Arroyo and M.A.S.D. de Barros, Text. Res. J., 87, 829 (2017); https://doi.org/10.1177/0040517516641357.

12. M. Shahid, Shahid-ul-Islam and F. Mohammad, J. Clean. Prod., 53, 310 (2013); https://doi.org/10.1016/i.jclepro.2013.03.031
13. Shahid-ul-Islam, M. Shahid and F. Mohammad, J. Clean. Prod., 57, 2 (2013); https://doi.org/10.1016/j.jclepro.2013.06.004.

14. B. Patel, Natural Dyes, In: Handbook of Textile and Industrial Dyeing, Elsevier, pp 395-424 (2011).

15. H. Schweppe, Handbuch der Naturfarbstoffe: Vorkommen, Verwendung, Nachweis: Germany (1992).

16. E. Dedhia, Colourage, 45, 45 (1998).

17. H. Bukhari, M. Heba and Q. Khadijah, Int. J. Technol. Res. Appl., 2, 2320 (2014).

18. S. Adeel, K.M. Zia, M. Abdullah and F. Rehman, M. Salman and M. Zuber, Nat. Prod. Res., 33, 2060 (2019); https://doi.org/10.1080/14786419.2018.1484466.

19. N. Baaka, A. Mahfoudhi, W. Haddar, M.F. Mhenni and Z. Mighri, Nat. Prod. Res., 31, 22 (2017); https://doi.org/10.1080/14786419.2016.1207072.

20. M.M. Hasan, K.A. Nayem, A.Y.M. Anwarul Azim and N.C. Ghosh, J. Text. 2015, Article ID 932627 (2015); https://doi.org/10.1155/2015/932627.

21. M.A. Bezerra, R.E. Santelli, E.P. Oliveira, L.S. Villar and L.A. Escaleira, Talanta, 76, 965 (2008); https://doi.org/10.1016/j.talanta.2008.05.019.

22. L. Mohajeri, H.A. Aziz, M.H. Isa and M.A. Zahed, Bioresour. Technol., 101, 893 (2010); https://doi.org/10.1016/j.biortech.2009.09.013.

23. D.C. Montgomery, Design and Analysis of Experiments, John Wiley \& Sons (2017).

24. E. Rahayuningsih, M.S. Pamungkas, M. Olvianas and A.D.P. Putera, J. Food Sci. Technol., 55, 1028 (2018); https://doi.org/10.1007/s13197-017-3016-7.

25. R. Mansour, B. Ezzili and M. Farouk, J. Text. Inst., 108, 528 (2017); https://doi.org/10.1080/00405000.2016.1172821.

26. K. Sinha, S. Chowdhury, P.D. Saha and S. Datta, Ind. Crops Prod.,, 41, 165 (2013); https://doi.org/10.1016/j.indcrop.2012.04.004.

27. N. Vedaraman, K. Sandhya, N. Charukesh, B. Venkatakrishnan, K. Haribabu, M. Sridharan and R. Nagarajan, Process Intensif., 114, 46 (2017); https://doi.org/10.1016/j.cep.2017.01.008.

28. S.E. Agarry and O.O. Ogunleye, J. Environ. Prot., 3, 748 (2012); https://doi.org/10.4236/jep.2012.38089.

29. J.P. Maran and S. Manikandan, Dyes and Pigment, 95, 465 (2012); https://doi.org/10.1016/j.dyepig.2012.06.007. 